\title{
Long-term outcomes of intervention between open repair and endovascular aortic repair for descending aortic pathologies: a propensity-matched analysis
}

\author{
Shin-Ah Son ${ }^{1} \mathbb{B}$, Hanna Jung ${ }^{2}$ [D and Joon Yong $\mathrm{Cho}^{2^{*}}$ (1)
}

\begin{abstract}
Background: The long-term complication rates of open repair and thoracic endovascular aortic repair (TEVAR) have not yet been determined. Therefore, this study aimed to compare the long-term outcomes and aortic reintervention rates between open repair and TEVAR in patients with descending thoracic aortic pathologies.

Methods: Between January 2002 and December 2017, 230 patients with descending thoracic aortic pathologies underwent surgery. Of these, 136 patients were included in this retrospective study: 45 patients (10, 2, and 33 with dissection, penetrating atherosclerotic ulcer, and pseudoaneurysm, respectively) underwent open repair and 91 patients (27, 1, and 63 with dissection, penetrating atherosclerotic ulcer, and pseudoaneurysm, respectively) underwent TEVAR. The primary end points were in-hospital mortality, and short-term complications. The secondary end points were long-term mortality and reintervention rates. Based on the propensity score matching (PSM), 35 patients who underwent open repair were matched to 35 patients who underwent TEVAR (ratio $=1: 1$ ).

Results: The mean follow-up period was $70.2 \pm 51.9$ months. Shorter intensive care unit and hospital stay were seen in the TEVAR group than in the open repair group before and after PSM ( $p<0.001$ and $p<0.001$, respectively). However, in-hospital mortality, and spinal cord ischemia were not significantly different among the two groups (before PSM: $p=0.068$ and $p=0.211$, respectively; after PSM: $p=0.303$ and $p=0.314$, respectively). The cumulative all-cause death and aorta-related death showed no significant differences between the two groups (before PSM: $p=0.709$ and $p=0.734$, respectively; after PSM: $p=0.888$ and $p=0.731$, respectively). However, aortic reintervention rates were higher in the TEVAR group than in the open repair group before and after PSM ( $p=0.006$ and $p=0.013$, respectively).

Conclusion: The TEVAR group was superior in short-term recovery outcomes but had higher reintervention rates compared to the open repair group. However, there were no significant differences in long-term survival between the two groups.
\end{abstract}

Keywords: Descending aorta, Endovascular repair, Graft replacement, Outcomes, Reintervention

*Correspondence: jycho@knu.ac.kr

${ }^{2}$ Department of Thoracic and Cardiovascular Surgery, School of Medicine, Kyungpook National University, Kyungpook National University Hospital,

130 Dongdeok-ro, Jung-gu, Daegu, Republic of Korea

Full list of author information is available at the end of the article

\section{Background}

The treatment of descending thoracic aortic pathologies is challenging and depends on its pathologies. Since the introduction of thoracic endovascular aortic repair (TEVAR), many reports have demonstrated that it is a safe and feasible alternative to the conventional open 
repair [1-3]. Typically, the success of this procedure is dictated by its favorable outcomes and ease of use [4]. Although the use of TEVAR has rapidly increased due to improved perioperative morbidity rates, significant postoperative complications associated with TEVAR contribute to its relatively poor results; these complications include, endoleak, stent-graft migration, retrograde type aortic dissection, new-onset dissection, and stent-graft infection $[3,5,6]$. In early clinical results with open repair versus TEVAR covered in previous reports $[3,6,7]$, there are little long-term data comparing two procedures. In particular, the durability and long-term complication rates of open repair and TEVAR have not yet been determined. We hypothesized that the advantages of TEVAR, which included less invasive and ease of use, will result in improved long-term outcomes for patients.

The purpose of this study was to compare long-term outcomes and reintervention rates between open repair and TEVAR in patients with descending aortic pathologies. To neutralize the effects of confounding independent variables such as unbalanced numbers (45:91) and age discrepancy, a propensity matched subsample of patients was created for an adequately powered analysis.

\section{Methods}

\section{Study population}

Between January 2002 and December 2017, 512 patients were diagnosed with descending thoracic aortic pathologies, comprising mainly dissection, pseudoaneurysm and penetrating atherosclerotic ulcer (PAU) at Kyungpook National University. Among them, 253 patients with uncomplicated descending aortic pathologies and who underwent medical therapy aimed at maintaining hemodynamic stability for promoting aortic stability were excluded; antihypertensive agents were administered to prevent aortic expansion. Furthermore, 29 additional patients who refused operation due to old age, financial problems, and poor general conditions were excluded as well. Out of the remaining 230 patients, 93 with traumatic aortic injury and hybrid aortic surgery who experienced cardiac arrest were excluded. Additional exclusion criteria were congenital aortic surgery including repair of coarctation of the aorta. The remaining 136 patients were included: Of these, 45 patients (10, 2, and 33 with dissection, PAU, and pseudoaneurysm, respectively) underwent open repair (the open repair group) and 91 patients (27, 1 , and 63 with dissection, PAU, and pseudoaneurysm, respectively) underwent TEVAR (the TEVAR group). Telephonic clinical assessments and outpatient clinical records were reviewed for these patients. The study design flowchart is demonstrated in Fig. 1.

Acute dissection was defined when the occurrence developed within 14 days from the first symptom.
Complicated aortic pathologies were defined as the presence of one or more of the following conditions: aortic maximum size $>5.5 \mathrm{~cm}$; resistant hypertension despite adequate medical therapy; recurrent or refractory pain; impending rupture; rupture with end-organ malperfusion; and extension of dissection. Aortic reintervention was delineated as the need for any surgical or endovascular interventions following the initial procedure during follow-up. In the TEVAR group, an endoleak represents as radiological evidence of blood flow outside the stent -graft according to published guidelines [8].

\section{Operative strategies}

Contrast-enhanced computed tomography $(\mathrm{CT})$ was performed for the preoperative assessment of descending thoracic aortic pathologies. Surgery was performed for patients with complicated acute or chronic descending aortic pathologies. The treatment modality was decided collaboratively by the cardiologist and cardiac surgeons who were involved in the patients' care; the decision was based on the patients' co-morbidities, functional status, anatomical feature of the lesion, and the appropriate of vascular access [9].

Open aortic repair was performed via left thoracotomy or median sternotomy. All procedures were performed with sequential clamping to minimize ischemic times. In case of left atrial-left femoral artery partial bypass, blood was drained from the left atrium via the inferior pulmonary vein and returned through the femoral artery. In case of circulatory arrest, bypass was initiated via the femoral artery and vein or the ascending aorta and right atrium. After the distal aortic arch was cross-clamped, the aorta was opened and a proximal anastomosis was constructed. If there was severe calcification, and friable tissue of the aorta or proximal clamp technically impossible, the patient was put under total circulatory arrest. Moderate hypothermia to $24{ }^{\circ} \mathrm{C}$ was achieved by gradual cooling, and circulation was arrested [10].

Preoperative CT were reviewed for the preoperative assessment of access routes for the feasibility of TEVAR. The scans were also reviewed to investigate the bilateral vertebral artery for assessing the subclavian steal syndrome with a policy of selective subclavian artery revascularization. All TEVAR procedures were performed via the transfemoral approach under general anesthesia. Perioperative anticoagulation with heparin was prescribed at a dose of 3000-5000 units. For patients with a healthy native aorta, stent-graft oversizing was considered $5-10 \%$, and excessive oversizing was considered over $20 \%$. The proximal landing zones in the aortic arch were classified as 0 to 4 according to Ishimaru's classification [11]. The proximal landing zone length was maintained at least $2 \mathrm{~cm}$ away from the lesion, and bypass was 


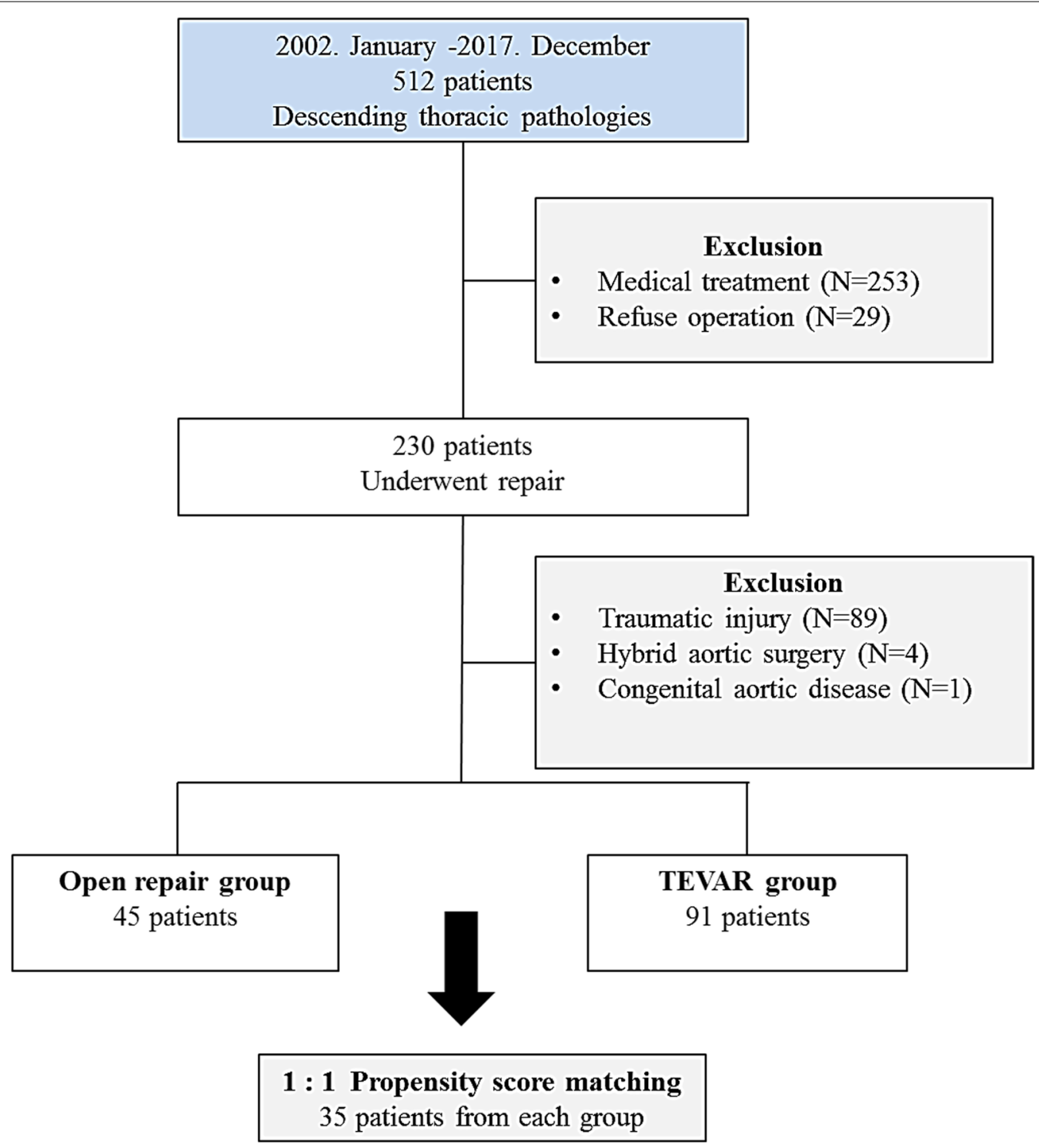

Fig. 1 Study design flowchart

performed if necessary, through a preoperative assessment. TEVAR was performed using S\&G SEAL Thoracic Stent-Grafts (S\&G Biotech, Seongnam, Korea) and Valiant Thoracic Stent-Grafts (Medtronic Vascular, Santa Rosa, CA, USA).

When comparing continuous variables, the Student's t-test and Wilcoxon test were used for parametric and nonparametric data, respectively, and are presented with the mean \pm standard deviation (SD) or as median and interquartile range (IQR). Categorical variables were reported as absolute numbers or percentages and the Fisher's exact test or Chi-square test was used for comparison. The Kaplan-Meier method was used to estimate survival. For statistical analyses, $p$-values $<0.05$ were deemed significant. Univariate and multivariate logistic regression models were utilized to determine independent risk factors. Hazard ratios (HRs) are presented with 95\% confidence intervals (CIs).

To reduce the effect of selection bias and potential confounding in this retrospective cohort study, estimated propensity scores were used to match two groups. This was computed for each patient using a logistic regression model including the following variables: age, proximal maximal aortic size, aortic pathology, and proximal aortic tear site. The propensity score model was well-calibrated (Hosmer-Lemeshow goodness-of-fit test; $p=0.784$ ) with 
good discrimination (c-statistic $=0.712$ ). To neutralize the effects of confounding variables, 35 patients in the open repair group were matched to 35 patients who underwent TEVAR using propensity score matching (PSM). The data were analyzed using SAS/STAT software, v. 9.4 (SAS Institute Inc., NC, USA) and SPSS 25 (IBM, Armonk, NY, USA).

\section{Results}

\section{Baseline characteristics of patients}

Baseline characteristics of the patients who underwent open repair and TEVAR are shown in Table 1 . The mean follow-up duration was $70.2 \pm 51.9$ months (range: 0.0-212.0 months). The median age of the patients differed significantly between the open repair and TEVAR groups, and were 56.0 years (range: 43.0-64.0 years) and 65.0 years (range: 57.0-72.0 years), respectively $(\mathrm{p}<0.001)$. Moreover, the incidence of connective tissue diseases was significantly higher in the open repair group than in the TEVAR group $(\mathrm{p}<0.001)$. After PSM, the baseline characteristics of the patients exhibited no significant differences between the two groups.

Descending thoracic aortic pathologies details of the patients are shown in Table 2. No variables differed significantly between the two groups, both before and after PSM.

Operative details are shown in Table 3. In the open repair group, circulatory arrest perfusion was performed most frequently $(60.0 \%)$, and thoracotomy was the most common approach $(60.0 \%)$. In the TEVAR group, zone 3 TEVAR was performed most frequently (40.7\%).

\section{Postoperative outcomes and complications}

Postoperative outcomes and complications are shown in Table 4. The patients in the open repair group significantly required more operative time, needed longer ventilator care, stayed longer in the intensive care unit, and had longer periods of hospitalization than those in the TEVAR group (all $\mathrm{p}<0.05$, respectively), before and after PSM, respectively.

Table 1 Baseline characteristics of patients

\begin{tabular}{|c|c|c|c|c|c|c|}
\hline \multirow[t]{2}{*}{ Characteristics } & \multicolumn{3}{|l|}{ Overall series } & \multicolumn{3}{|l|}{ After matching } \\
\hline & $\begin{array}{l}\text { Open repair } \\
\mathrm{N}=45\end{array}$ & $\begin{array}{l}\text { TEVAR } \\
\mathrm{N}=91\end{array}$ & $p$-value & $\begin{array}{l}\text { Open repair } \\
\mathrm{N}=35\end{array}$ & $\begin{array}{l}\text { TEVAR } \\
\mathrm{N}=35\end{array}$ & $p$-value \\
\hline Age (years) & $56.0(43.0-64.0)$ & $65.0(57.0-72.0)$ & $<0.001$ & $60.0(49.0-69.0)$ & $59.0(51.0-68.0)$ & 0.967 \\
\hline Men & $31(30.1)$ & $72(69.9)$ & 0.279 & $25(71.4)$ & $30(85.7)$ & 0.145 \\
\hline Height (cm) & $167 \pm 10.0$ & $166 \pm 9.0$ & 0.623 & $164.8 \pm 10.1$ & $168.3 \pm 7.6$ & 0.112 \\
\hline Weight (kg) & $66.1 \pm 13.2$ & $64.9 \pm 11.0$ & 0.584 & $65.7 \pm 12.9$ & $68.9 \pm 12.4$ & 0.283 \\
\hline Initial SBP (mmHg) & $133.5 \pm 34.2$ & $141.3 \pm 29.3$ & 0.208 & $135.7 \pm 37.3$ & $145.5 \pm 27.1$ & 0.215 \\
\hline Hypertension & $30(66.7)$ & $66(72.5)$ & 0.480 & $26(74.3)$ & $25(71.4)$ & 0.788 \\
\hline Diabetes & $5(11.1)$ & $12(13.2)$ & 0.731 & $5(14.3)$ & $1(2.9)$ & 0.088 \\
\hline Current smoking & $20(44.4)$ & $36(39.6)$ & 0.586 & $16(45.7)$ & $16(45.7)$ & 1.000 \\
\hline Obesity & $2(4.4)$ & $3(3.3)$ & 0.738 & $2(5.7)$ & $2(5.7)$ & 1.000 \\
\hline CAOD & $4(8.9)$ & $10(11.0)$ & 0.705 & $3(8.6)$ & $6(17.1)$ & 0.284 \\
\hline PAOD & $4(18.2)$ & 18 (81.8) & 0.105 & $4(11.4)$ & $5(14.3)$ & 0.721 \\
\hline COPD & $2(4.4)$ & $4(4.4)$ & 0.990 & $2(5.7)$ & $2(5.7)$ & 1.000 \\
\hline Cerebrovascular accident & $1(2.2)$ & $11(12.1)$ & 0.056 & $1(2.9)$ & $4(11.4)$ & 0.164 \\
\hline Acute kidney injury & $2(4.4)$ & $5(5.5)$ & 0.794 & $2(5.7)$ & $1(2.9)$ & 0.555 \\
\hline Chronic renal failure & $4(8.9)$ & $7(7.7)$ & 0.810 & $2(5.7)$ & $3(8.6)$ & 0.643 \\
\hline Previous cardiac operation & $10(22.2)$ & $18(19.8)$ & 0.740 & $3(8.6)$ & $6(17.1)$ & 0.284 \\
\hline Connective tissue disease & $8(17.8)$ & $1(1.1)$ & $<0.001$ & $2(5.7)$ & $0(0.0)$ & 0.151 \\
\hline \multicolumn{7}{|l|}{ Preoperative status } \\
\hline Shock & $7(15.6)$ & $5(5.5)$ & 0.052 & $5(14.3)$ & $3(8.6)$ & 0.654 \\
\hline Hemoptysis & $6(13.3)$ & $11(12.1)$ & 0.836 & $4(11.4)$ & $4(11.4)$ & 1.000 \\
\hline Persistent pain & $37(82.2)$ & $73(80.2)$ & 0.780 & $30(85.7)$ & $27(77.1)$ & 0.356 \\
\hline Neurologic deficit & $3(6.7)$ & $3(3.3)$ & 0.368 & $2(5.7)$ & $0(0.0)$ & 0.151 \\
\hline
\end{tabular}

Values are presented as the median (interquartile range), mean \pm standard deviation or number of patients (\%) 
Table 2 Descending thoracic aortic diseases details of patients

\begin{tabular}{|c|c|c|c|c|c|c|}
\hline \multirow[t]{2}{*}{ Characteristics } & \multicolumn{3}{|l|}{ Overall series } & \multicolumn{3}{|c|}{ After matching } \\
\hline & $\begin{array}{l}\text { Open repair } \\
\mathrm{N}=45\end{array}$ & $\begin{array}{l}\text { TEVAR } \\
\mathrm{N}=91\end{array}$ & $p$-value & $\begin{array}{l}\text { Open repair } \\
\mathrm{N}=35\end{array}$ & $\begin{array}{l}\text { TEVAR } \\
\mathrm{N}=35\end{array}$ & $p$-value \\
\hline Acute & $15(33.3)$ & $20(22.0)$ & 0.154 & $13(37.1)$ & $7(20.0)$ & 0.112 \\
\hline Rupture & $19(42.2)$ & $21(23.1)$ & 0.021 & $16(45.7)$ & $9(25.7)$ & 0.081 \\
\hline \multicolumn{7}{|l|}{ Preoperative diagnosis } \\
\hline Dissection & $10(22.2)$ & $27(29.7)$ & 0.358 & $8(22.9)$ & $10(28.6)$ & 0.584 \\
\hline PAU & $2(4.4)$ & $1(1.1)$ & 0.211 & $2(5.7)$ & $0(0.0)$ & 0.151 \\
\hline Pseudoaneurysm & $33(73.3)$ & $63(69.2)$ & 0.621 & $25(71.4)$ & $25(71.4)$ & 1.000 \\
\hline Arch involvement & $12(26.7)$ & $14(15.4)$ & 0.115 & $9(25.7)$ & $4(11.4)$ & 0.124 \\
\hline Maximal aortic size (mm) & $54.9 \pm 4.7$ & $51.5 \pm 4.5$ & 0.471 & $52.8 \pm 4.8$ & $51.8 \pm 3.7$ & 0.985 \\
\hline \multicolumn{7}{|l|}{ Aortic tear site } \\
\hline Arch & $5(11.1)$ & $4(4.4)$ & 0.138 & $4(11.4)$ & $1(2.9)$ & 0.164 \\
\hline Isthmus & $8(17.8)$ & $34(37.4)$ & 0.020 & $6(17.1)$ & $12(34.3)$ & 0.101 \\
\hline Descending & $32(71.1)$ & $53(58.2)$ & 0.145 & $25(71.4)$ & $22(62.9)$ & 0.445 \\
\hline Malperfusion & $5(11.1)$ & $3(3.3)$ & 0.068 & $3(8.6)$ & $0(0.0)$ & 0.077 \\
\hline CSF drainage & $14(31.1)$ & $17(18.7)$ & 0.104 & $8(22.9)$ & $7(20.0)$ & 0.771 \\
\hline Emergency & $17(37.8)$ & $28(30.8)$ & 0.414 & $16(45.7)$ & $9(25.7)$ & 0.081 \\
\hline
\end{tabular}

Values are presented as mean \pm standard deviation or number of patients (\%)

TEVAR thoracic endovascular aortic repair, PAU penetrating atherosclerotic ulcer, CSF cerebrospinal fluid

Postoperative acute kidney injury (AKI) was higher in the open repair group before and after PSM $(p=0.006$ and $p=0.019$, respectively); however, there was no difference between the two groups in the AKI requiring dialysis before and after PSM $(p=0.192$ and $p=0.303$, respectively). AKI progressed to chronic renal failure (CRF) in only two patients in the TEVAR group. Bleeding and wound complications including wound dehiscence and infection, were frequently observed in the open repair group before PSM $(p=0.001$ and $p=0.001$, respectively); however, there were no statistical difference between the two groups after PSM ( $p=0.133$ and $p=0.057$, respectively). In addition, there was no statistical difference in occurrence of spinal cord ischemia (SCI) between the two groups before and after PSM $(p=0.211$ and $p=0.314$, respectively).

There were no statistical difference in-hospital mortality and 30-day mortality between the two groups before PSM ( $p=0.068$ and $p=0.138$, respectively). Moreover, same as before PSM, in-hospital mortality and 30-day mortality showed no statistical difference between the two groups ( $p=0.303$ and $p=0.643$, respectively).

In-hospital mortality was observed in five patients in the open repair group (11.1\%), of whom four and one died of acute aorta-related complications and hospitalacquired pneumonia, respectively. In the TEVAR group, among three patients (3.3\%), two patients died of delayed rupture after stent insertion and one patient died of aspiration pneumonia.

\section{Reintervention}

Reintervention data associated with specific treatments are depicted in Table 5. In the open repair group, five patients (11.1\%) required reinterventions; and four patients experienced new onset aortic expansion. Among these patients, secondary open repair surgery was performed in three patients, and TEVAR was performed in one patient. In the TEVAR group, 22 patients (48.9\%) required reintervention; twelve patients had endoleaks and four patient developed fistula, such as aortobronchial fistula or aortoesophageal fistula.

In the overall series, freedom from aortic reintervention at 1,5 , and 10 years in the open repair group was $97.1 \% \pm 0.1 \%, 94.2 \% \pm 0.1 \%$, and $87.1 \% \pm 0.0 \%$, respectively. The corresponding rates in the TEVAR group were $93.2 \% \pm 0.1 \%, 68.4 \% \pm 0.1 \%$, and $62.2 \% \pm 0.0 \%$, respectively. After PSM, the rate of freedom from aortic reintervention at 1,5 , and 10 years in the open group was $100 \% \pm 0.0 \%, 96.4 \% \pm 0.1 \%$, and $92.2 \% \pm 0.1 \%$, respectively. In the TEVAR group, the corresponding values were $91.0 \% \pm 0.1 \%, 78.1 \% \pm 0.1 \%$, and $66.8 \% \pm 0.1 \%$, respectively. Freedom from aortic reintervention (Fig. 2) was lower in the TEVAR group than in the open repair group before and after PSM ( $p=0.006$ and $p=0.013$, respectively).

A multivariable Cox proportional hazard model is shown in Table 6. 
Table 3 Operative details

\begin{tabular}{|c|c|}
\hline Open repair & $(\mathrm{N}=45)$ \\
\hline \multicolumn{2}{|l|}{ Perfusion method } \\
\hline Left atrium- Femoral artery partial bypass & $15(33.3)$ \\
\hline Partial Shunt ${ }^{\mathrm{a}}$ & $3(6.67)$ \\
\hline Circulatory arrest & $27(60.0)$ \\
\hline Femoral artery-Femoral vein & $9(20.0)$ \\
\hline Aorta-Right atrium & $18(40.0)$ \\
\hline \multicolumn{2}{|l|}{ Operative Approach } \\
\hline Median sternotomy & $10(22.2)$ \\
\hline Median sternotomy + Thoracotomy & $8(17.7)$ \\
\hline Thoracotomy & $27(60.0)$ \\
\hline Cardiopulmonary bypass time (min) & $191.1 \pm 104.3$ \\
\hline Cross clamp time (min) & $60.5 \pm 49.9$ \\
\hline Circulatory arrest time (min) & $25.5 \pm 31.4$ \\
\hline TEVAR & $(N=91)$ \\
\hline Number of devices & $1.2 \pm 0.4$ \\
\hline Proximal stent size (mm) & $35.1 \pm 4.7$ \\
\hline Stent Length (mm) & $140.2 \pm 28.2$ \\
\hline Zone 0 & $\begin{array}{l}6(6.6) \\
\text { Total debranching bypass with TEVAR }\end{array}$ \\
\hline Zone 1 & $\begin{array}{l}1(1.1) \\
\text { BCA to LCCA and LCCA to LSCA bypass }\end{array}$ \\
\hline Zone 2 & $\begin{array}{l}25 \text { ( } 27.5) \\
\text { LCCA to LSCA bypass in } 5 \text { patients }\end{array}$ \\
\hline Zone 3 & $37(40.7)$ \\
\hline Zone 4 & $22(24.2)$ \\
\hline
\end{tabular}

Values are presented as mean \pm standard deviation or number of patients (\%)

TEVAR thoracic endovascular aortic repair, BCA brachiocephalic artery, LCCA left common carotid artery, LSCA left subclavian artery

a Graft placed proximal and distal to the injury site

\section{Change in the aorta size after the repair}

Figure 3 shows the changes in the aorta size after the repair. During the following 5 years, the maximal aortic diameter was more reduced in the open repair group as compared to that in the TEVAR group before and after PSM ( $p=0.004$ and $p=0.05$, respectively). The maximal aortic diameter decreased from $55.4 \pm 18.2 \mathrm{~mm}$ to $40.07 \pm 11.0 \mathrm{~mm}$ in the open repair group as we expected. Meanwhile the maximal aortic diameter increased from $52.0 \pm 14.7 \mathrm{~mm}$ to $56.8 \pm 19.1 \mathrm{~mm}$ in the TEVAR group.

\section{Survival}

In the open repair group, the overall mortality was $42.2 \%(19 / 45)$, and the aorta-related mortality was $17.8 \%$ (8/45) during follow-up. Aorta-unrelated death secondary to cancer occurred in three patients, while three patients died of pneumonia. Late deaths secondary to unknown causes occurred in four patients. In the TEVAR group, the overall mortality was $35.2 \%$
(32/91), and the aorta-related mortality was $12.1 \%$ (11/91) during follow-up. Aorta-unrelated death secondary to cancer occurred in three patients, while two patients died of pneumonia. Late deaths secondary to unknown causes occurred in 10 patients.

The cumulative survival of all-cause death did not differ significantly between the two groups, neither before nor after PSM. Additionally, the cumulative survival rates from aorta-related deaths were also not significantly different between the two groups, before and after PSM (Fig. 4a, b).

A multivariable Cox proportional hazard model identified that age $>80$ years, systolic blood pressure $<90 \mathrm{mmHg}$, diabetes, preoperative chronic renal failure, and aortic arch involvement were the predictive factors in the in overall series; after PSM analysis, age $>80$ years, and aortic arch involvement $(\mathrm{p}=0.024$ and $\mathrm{p}=0.048$, respectively) were the independent predictors of aorta-related mortality (Table 7). 
Table 4 Postoperative outcomes and complications

\begin{tabular}{|c|c|c|c|c|c|c|}
\hline \multirow[t]{2}{*}{ Characteristics } & \multicolumn{3}{|l|}{ Overall series } & \multicolumn{3}{|c|}{ After matching } \\
\hline & $\begin{array}{l}\text { Open repair } \\
\mathrm{N}=45\end{array}$ & $\begin{array}{l}\text { TEVAR } \\
\mathrm{N}=91\end{array}$ & $p$-value & $\begin{array}{l}\text { Open repair } \\
\mathrm{N}=35\end{array}$ & $\begin{array}{l}\text { TEVAR } \\
\mathrm{N}=35\end{array}$ & $p$-value \\
\hline \multicolumn{7}{|l|}{ Outcomes } \\
\hline Operative time & $420.6 \pm 182.9$ & $149.3 \pm 92.9$ & $<0.001$ & $386.7 \pm 124.5$ & $150.9 \pm 88.7$ & $<0.001$ \\
\hline Postop Hospital stay (day) & $41.5 \pm 42.7$ & $18.3 \pm 16.0$ & $<0.001$ & $34.2 \pm 26.5$ & $15.1 \pm 8.6$ & $<0.001$ \\
\hline Total ICU stay (day) & $19.6 \pm 31.2$ & $5.7 \pm 14.0$ & $<0.001$ & $17.7 \pm 24.6$ & $3.7 \pm 5.4$ & 0.002 \\
\hline Total ventilator care (min) & $145.7 \pm 334.1$ & $33.6 \pm 158.2$ & 0.009 & $111.9 \pm 225.4$ & $11.9 \pm 48.6$ & 0.008 \\
\hline Reintubation & $7(15.6)$ & $4(4.4)$ & 0.025 & $5(14.3)$ & $1(2.9)$ & 0.088 \\
\hline \multicolumn{7}{|l|}{ Complications } \\
\hline Acute kidney injury & $19(42.2)$ & $18(19.8)$ & 0.006 & $15(42.9)$ & $6(17.1)$ & 0.019 \\
\hline Dialysis & $6(13.3)$ & $6(6.6)$ & 0.192 & $3(8.6)$ & $1(2.9)$ & 0.303 \\
\hline Hematologic complications & $1(2.2)$ & $2(2.2)$ & 0.993 & $1(2.9)$ & $0(0.0)$ & 0.314 \\
\hline Bleeding & $9(20.0)$ & $3(3.3)$ & 0.001 & $6(17.1)$ & $2(5.7)$ & 0.133 \\
\hline Spinal cord injury & $2(4.4)$ & $1(1.1)$ & 0.211 & $1(2.9)$ & $0(0.0)$ & 0.314 \\
\hline Stroke & $3(6.7)$ & $1(1.1)$ & 0.071 & $2(5.7)$ & $0(0.0)$ & 0.151 \\
\hline Pulmonary complications & $9(20.0)$ & $7(7.7)$ & 0.036 & $7(20.0)$ & $2(5.7)$ & 0.074 \\
\hline Wound complications & $12(26.7)$ & $6(6.6)$ & 0.001 & $9(25.7)$ & $3(8.6)$ & 0.057 \\
\hline In-hospital mortality & $5(11.1)$ & $3(3.3)$ & 0.068 & $3(8.6)$ & $1(2.9)$ & 0.303 \\
\hline 30-day mortality & $5(11.1)$ & $4(4.4)$ & 0.138 & $3(8.6)$ & $2(5.7)$ & 0.643 \\
\hline
\end{tabular}

Values are presented as mean \pm standard deviation or number of patients (\%)

TEVAR thoracic endovascular aortic repair, Postop postoperative, ICU intensive care unit

Table 5 Aortic reintervention details

\begin{tabular}{|c|c|c|}
\hline Cause of Reintervention & Open repair $(\mathrm{N}=5,11.1 \%)$ & TEVAR $(\mathrm{N}=22,48.9 \%)$ \\
\hline New onset dissection/expansion & $\begin{array}{l}\text { Aorta replacement:3 } \\
\text { TEVAR:1 }\end{array}$ & $\begin{array}{l}\text { Aorta replacement:2 } \\
\text { TEVAR:1 }\end{array}$ \\
\hline Fistula formation & Aorta replacement and lobectomy:1 & $\begin{array}{l}\text { Aorta replacement and } \\
\text { lobectomy:4 } \\
\text { Aorta replacement and } \\
\text { esophagotomy: } 1 \\
\text { TEVAR: } 1\end{array}$ \\
\hline Endoleak & & $\begin{array}{l}\text { TEVAR: } 12 \\
\text { LSCA plug obliteration: } 1\end{array}$ \\
\hline Infection & & Aorta replacement:1 \\
\hline
\end{tabular}

TEVAR thoracic endovascular aortic repair, LSCA left subclavian artery

\section{Discussion}

The prevalence of descending thoracic aortic pathologies, comprising mainly of aneurysm, dissection, and PAU, which eventually rupture if not recognized and treated appropriately, are increasing among our population [12]. Since, the report on the first successful open repair of a descending thoracic aortic aneurysm with a prosthetic graft in 1953 by De Bakey and Cooley [13], an open surgical repair for treating descending thoracic aortic disease has been the gold standard for 50 years [13-16]. Despite remarkably improved operative techniques and maximized organ protection, open repair of the descending thoracic aorta is still associated with high complications, including intraoperative and postoperative death, hemorrhage, stroke, and paraplegia $[9,17]$.

Dake et al. [14] proposed an alternate method of TEVAR which sought to provide better clinical outcomes in patients who were deemed to be at high risk for open repair or were typically considered nonsurgical candidates. Therefore, TEVAR has shown significantly improved early quality of life versus open repair and a general trend toward better short-term perioperative survival and freedom from major complications $[1,3,4,18]$. However, TEVAR has anatomic restrictions 

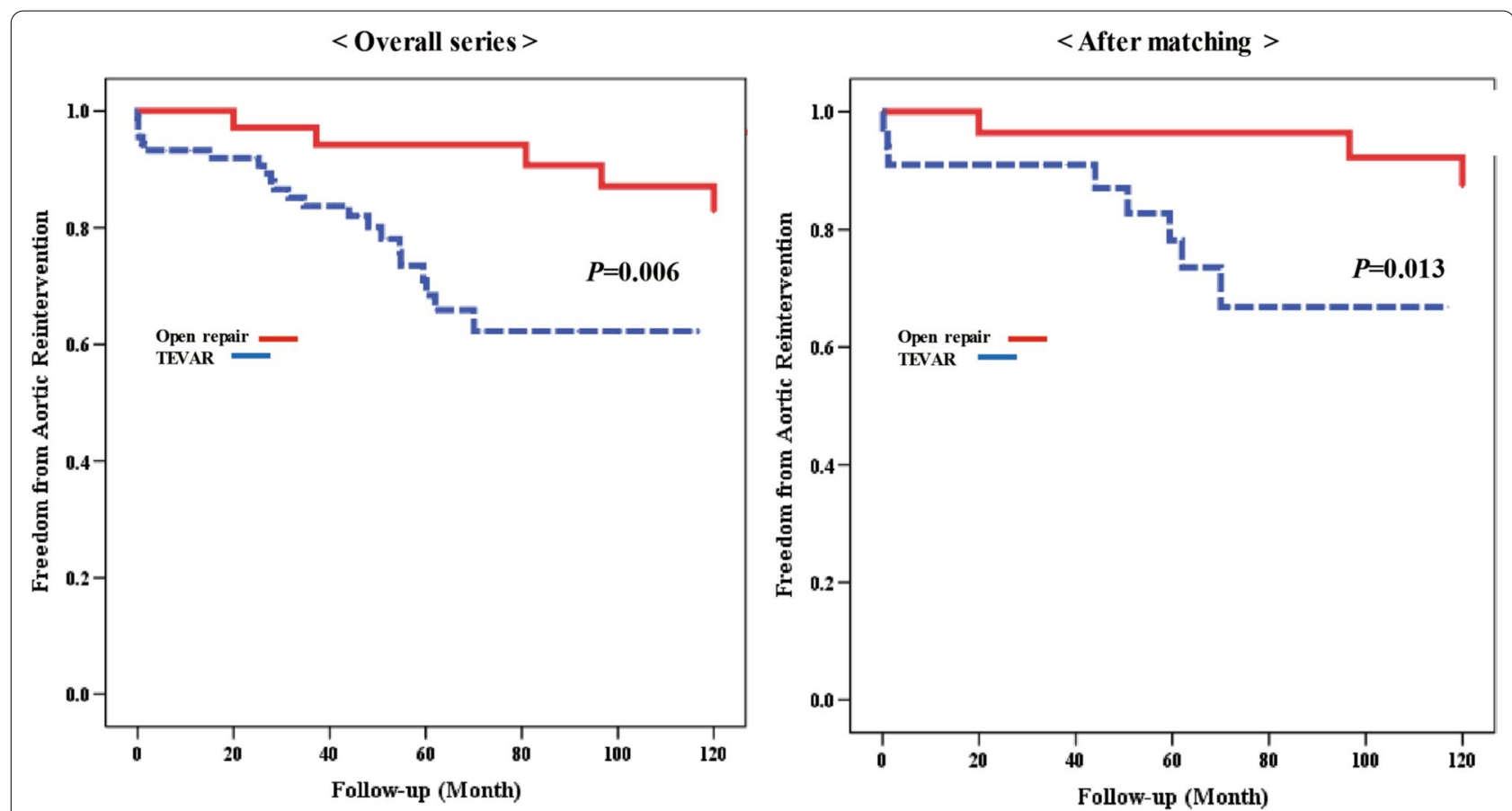

Fig. 2 Freedom from aortic reintervention before propensity matching and after propensity matching

Table 6 Cox proportional hazard regression analysis for reintervention

\begin{tabular}{|c|c|c|c|c|c|c|c|c|}
\hline \multirow[t]{3}{*}{ Variable } & \multicolumn{4}{|l|}{ Overall series } & \multicolumn{4}{|c|}{ After matching } \\
\hline & \multicolumn{2}{|l|}{ Univariate } & \multicolumn{2}{|l|}{ Multivariate } & \multicolumn{2}{|l|}{ Univariate } & \multicolumn{2}{|l|}{ Multivariate } \\
\hline & $\mathrm{HR}(95 \% \mathrm{Cl})$ & $p$-value & $\mathrm{HR}(95 \% \mathrm{Cl})$ & $p$-value & $\mathrm{HR}(95 \% \mathrm{Cl})$ & $p$-value & $\mathrm{HR}(95 \% \mathrm{Cl})$ & $p$-value \\
\hline Male & $2.0(0.6-5.8)$ & 0.191 & & & $0.2(0.0-2.2)$ & 0.230 & & \\
\hline Hemoptysis & $2.8(1.3-6.9)$ & 0.026 & $3.8(1.2-11.3)$ & 0.016 & $8.5(2.4-29.3)$ & 0.001 & $6.8(1.3-34.7)$ & 0.021 \\
\hline Hoarseness & $2.2(0.8-9.0)$ & 0.102 & & & $1.6(0.2-13.2)$ & 0.619 & & \\
\hline Hypertension & $0.2(0.5-2.9)$ & 0.595 & & & $4.4(0.5-34.9)$ & 0.151 & $7.9(0.8-73.1)$ & 0.048 \\
\hline Diabetes & $2.0(0.7-5.4)$ & 0.148 & & & $1.3(0.2-10.7)$ & 0.766 & & \\
\hline CAOD & $2.5(0.9-6.7)$ & 0.059 & & & $2.2(0.5-10.6)$ & 0.210 & & \\
\hline PAOD & $1.7(0.7-4.4)$ & 0.210 & & & $1.9(0.4-8.9)$ & 0.400 & & \\
\hline COPD & $3.4(1.0-11.4)$ & 0.046 & & & $4.4(0.9-21.2)$ & 0.063 & & \\
\hline Cerebrovascular accident & $2.2(0.7-6.4)$ & 0.144 & & & $1.7(0.2-14.2)$ & 0.579 & & \\
\hline Acute kidney injury & $1.1(0.1-7.4)$ & 0.994 & & & $5.1(0.6-41.2)$ & 0.124 & & \\
\hline Previous cardiac operation & $1.1(0.6-3.4)$ & 0.388 & & & $3.2(0.8-12.4)$ & 0.082 & $6.81(1.3-34.9)$ & 0.021 \\
\hline
\end{tabular}

$H R$ hazard ratio, $\mathrm{Cl}$ confidence interval, $C A O D$ coronary artery occlusive disease, $P A O D$ peripheral artery occlusive disease, $C O P D$ chronic obstructive pulmonary disease

such as severe thoracic aortic tortuosity, short landing and sealing zones, and extensive mural thrombus. These are the limiting factors, although a seemingly infinite variety of debranching and bypass procedures can be applied to extend either the proximal or distal sealing zones $[6,19]$. Furthermore, significant complications related to stent-grafts were always implied $[3,5$, 17].
Patients who underwent TEVAR have a tendency to have a worse prognosis and older age, with multiple comorbidities, than patients who underwent open repair. Due to the relative lack of data supporting the long-term reliability of TEVAR, open repair procedure has been preferentially offered to younger patients $[4,12]$. Therefore, in this study, to neutralize the effects of age difference that could potentially unmask a mortality benefit, 

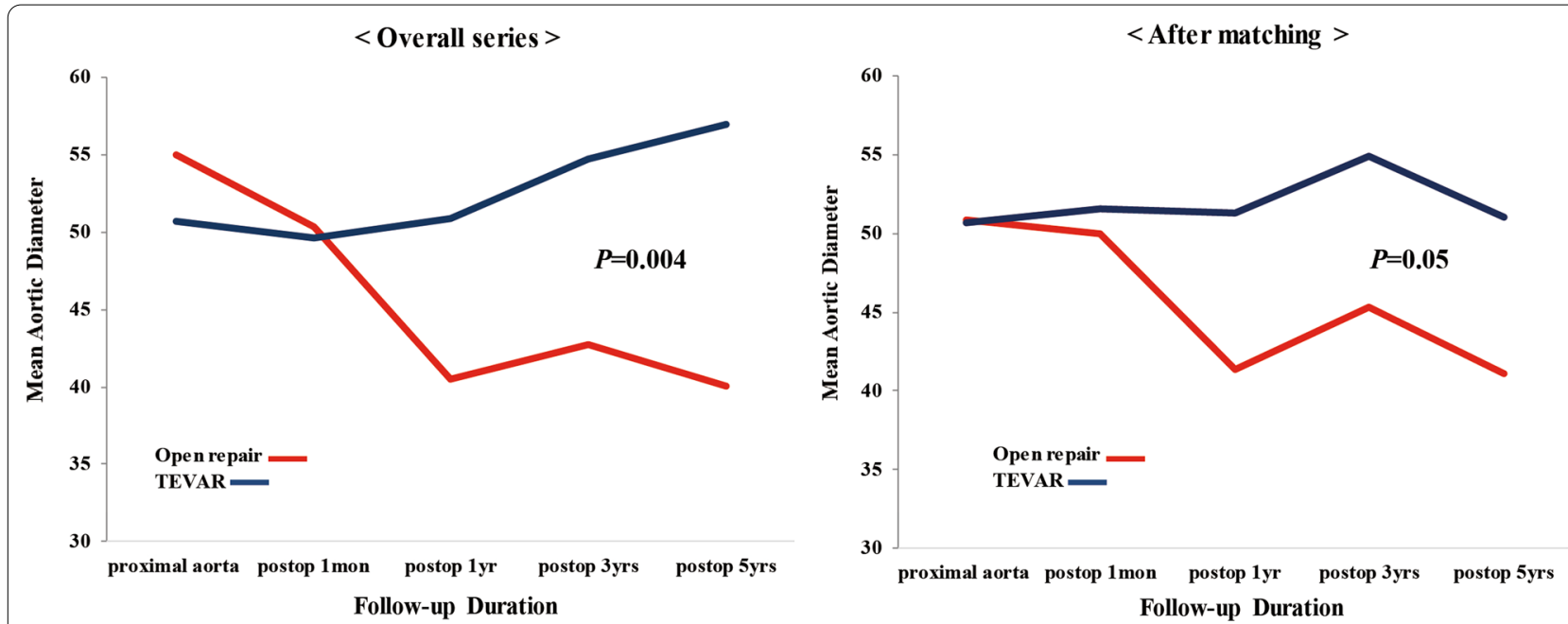

Fig. 3 Changes in aortic diameters over time before propensity matching and after propensity matching

PSM was performed between the two groups to perform an adequately powered analysis.

In the present study, the operative time, postoperative length of stay, and procedure-related complications showed better results with TEVAR before and after PSM. Not surprisingly, TEVAR was considering as the procedure involved no aortic cross-clamping, ischemic time, or thoracotomy [4]. In open repair cases, some disadvantages of deep hypothermia, including coagulopathy which caused difficulty in controlling bleeding, retraction injury to a heparinized lung, cold injury to the lung, and a profound inflammatory response from the bypass circuit [20]. Regarding the in-hospital mortality in the open repair group, in the present study, one patient died of pneumonia. AKI is another important complication and regarded as a marker of increased early or late morbidity and mortality after open repair or TEVAR [21]. Patients who underwent TEVAR were older and tended to receive larger amounts of contrast agent, which was not safe considering the risk of AKI. In the present study, postoperative AKI was higher in the open repair group (42.2\%), and dialysis was performed in $13.3 \%$ of the patients in this group. Eighteen patients who underwent TEVAR (19.8\%) had an AKI, six patients in the TEVAR group experienced AKI requiring dialysis. Before and after PSM, AKI was higher in the open repair group; however, there was no statistical difference in the requirement of dialysis between the two groups.

Although a short-term hospital outcome is more favorable for TEVAR, aorta-related complications are more frequent for TEVAR. Five patients (11.1\%) in the open repair group underwent reintervention, and the most common cause of reintervention was newonset aortic dissection or expansion. In the case of
TEVAR, the most common cause of reintervention was endoleaks. Twenty-two (48.9\%) patients who underwent reintervention showed no in-hospital mortality in the TEVAR; however, seven patients showed late mortality, one patient died of aortobronchial fistula and one patient died of sepsis due to stent-graft infection. Ascending aortic replacement was performed in one patient with retrograde aortic dissection, four patients with aortabronchial fistula underwent aorta replacement and lobectomy, and one patient with aortoesophageal fistula underwent aorta replacement and esophagotomy, and showed late mortality. Additionally, eight patients who were initially offered TEVAR, later crossed over to open repair due to difficult anatomy or other reasons.

In the open repair cases, high-volume centers reported mortality and neurological morbidity rates ranging from $5.4 \%$ to $7.2 \%$ for mortality, $2.1 \%$ to $6.2 \%$ for permanent stroke, $5.7 \%$ for permanent paraparesis, and $0.8 \%$ to $2.3 \%$ for permanent paralysis $[22,23]$. In the TEVAR cases, the perioperative results for the three stent-graft trials showed 1.9 to $2.1 \%$ for mortality, 2.4 to $4 \%$ for stroke, 4.4 to $7.2 \%$ for permanent paraparesis, and 1.3 to $3 \%$ for permanent paralysis $[1,2,24]$. In the present study, the open repair group showed $63.8 \%$ of overall 10 -year survival rate, $84.3 \%$ of aorta-related 10 -year survival rate, $6.7 \%$ of stroke, and $4.4 \%$ of SCI (after PSM, $65.4 \%, 88.5 \%$, $5.7 \%$, and $2.9 \%$, respectively). In TEVAR, overall 10-year survival rate was $56.5 \%$, aorta-related 10 -year survival rate $81.3 \%, 1.1 \%$ stroke, and $1.1 \%$ SCI (after PSM, $64.2 \%$, $88.7 \%, 0.0 \%, 0.0 \%$, respectively). Although mortality was higher than previous large-scale studies, it was difficult to compare our results because previous reports did not have long-term follow-up data. 

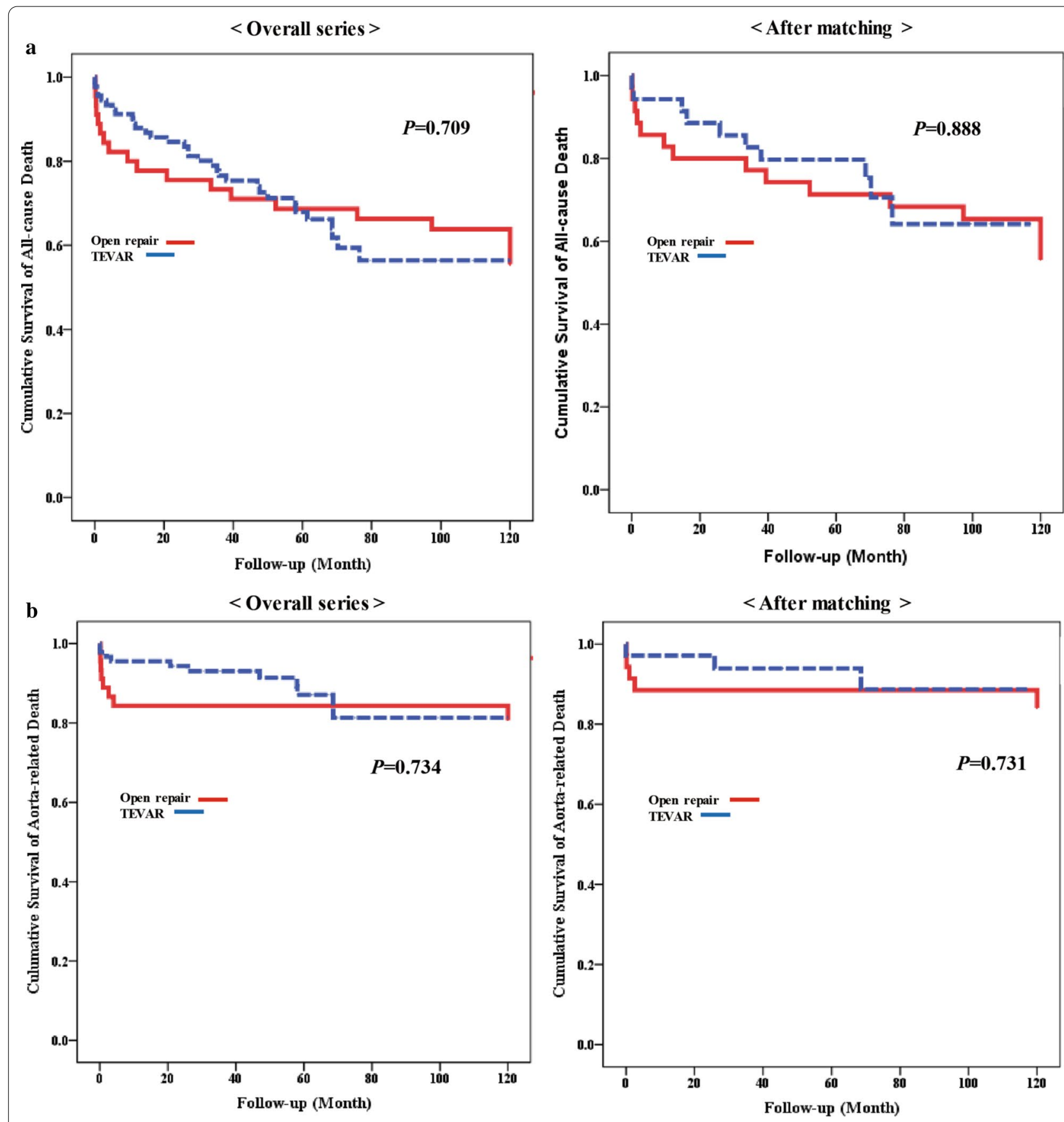

Fig. 4 Cumulative survival of all-cause death and aorta-related death

The existing literature on TEVAR versus open surgical repair suggests that the short-term benefit of TEVAR is lost as early as within 1-2 years from the surgery [3-7]. For mid-term outcomes, analysis of the Medicare database from 2004 to 2007 showed that TEVAR offered a significant perioperative survival advantage when compared to open repair, regardless of the indication for repair. However, the 5-year survival in the Medicare population was similar between the two cohorts [25]. In another study, Goodney et al. [26] reported patients with intact thoracic aortic aneurysm who underwent TEVAR had a significantly worse survival at 1 year than patients who underwent open repair (87\% for open repair and $82 \%$ for TEVAR; $p=0.001)$ and 5 years $(72 \%$ for open repair and $62 \%$ for TEVAR; $p=0.001$ ) than patients who underwent open repair. 
Table 7 Cox proportional hazard regression analysis for aorta-related mortality

\begin{tabular}{|c|c|c|c|c|c|c|c|c|}
\hline \multirow[t]{3}{*}{ Variable } & \multicolumn{4}{|l|}{ Overall series } & \multicolumn{4}{|c|}{ After matching } \\
\hline & \multicolumn{2}{|l|}{ Univariate } & \multicolumn{2}{|l|}{ Multivariate } & \multicolumn{2}{|l|}{ Univariate } & \multicolumn{2}{|l|}{ Multivariate } \\
\hline & $\mathrm{HR}(95 \% \mathrm{Cl})$ & $p$-value & $\mathrm{HR}(95 \% \mathrm{Cl})$ & $p$-value & $\mathrm{HR}(95 \% \mathrm{Cl})$ & $p$-value & $\mathrm{HR}(95 \% \mathrm{Cl})$ & $p$-value \\
\hline Age $>80$ years & $5.9(1.3-25.9)$ & 0.018 & $16.7(2.7-104.3)$ & 0.002 & $9.9(1.2-83.4)$ & 0.031 & $24.0(1.5-378.1)$ & 0.024 \\
\hline $\mathrm{SBP}<90 \mathrm{mmHg}$ & $2.9(0.9-8.9)$ & 0.058 & $6.0(1.6-22.4)$ & 0.008 & $2.6(0.5-13.3)$ & 0.241 & & \\
\hline Hemoptysis & $2.5(0.9-7.0)$ & 0.077 & & & $5.2(1.2-22.0)$ & 0.023 & & \\
\hline Dissection & $0.7(0.3-1.4)$ & 0.356 & & & $0.4(0.0-3.3)$ & 0.392 & & \\
\hline Pseudoaneurysm & $1.4(0.7-2.6)$ & 0.333 & & & $2.8(0.3-23.2)$ & 0.329 & & \\
\hline Arch involvement & $3.5(1.4-8.7)$ & 0.007 & $5.4(1.8-16.1)$ & 0.002 & $5.1(1.3-20.9)$ & 0.022 & $14.5(1.0-211.5)$ & 0.048 \\
\hline Maximal aortic size $>50 \mathrm{~mm}$ & $3.1(0.9-10.8)$ & 0.068 & & & $3.8(0.5-31.9)$ & 0.200 & & \\
\hline Malperfusion & $2.3(0.5-10.1)$ & 0.210 & & & $5.2(0.6-43.9)$ & 0.128 & & \\
\hline Chronic renal failure & $7.0(2.4-20.3)$ & 0.000 & $5.7(1.2-26.8)$ & 0.027 & $8.4(1.5-46.7)$ & 0.015 & & \\
\hline eGFR & $1.2(1.1-1.3)$ & 0.001 & & & $1.1(0.9-1.5)$ & 0.211 & & \\
\hline Diabetes & $2.8(1.0-7.8)$ & 0.047 & $3.1(0.9-10.7)$ & 0.049 & $4.2(0.8-20.9)$ & 0.080 & & \\
\hline COPD & $2.7(0.6-11.9)$ & 0.178 & & & $0.1(0.0-34.8)$ & 0.654 & & \\
\hline
\end{tabular}

$H R$ hazard ratio, $\mathrm{Cl}$ confidence interval, SBP systolic blood pressure, eGFR estimated glomerular filtration rate, COPD chronic obstructive pulmonary disease

Chiu et al. [27] reported that open surgical repairs of descending thoracic aortic aneurysms between 1999 and 2010 were associated with increased odds of early postoperative mortality, but reduced late hazard of death. Despite the improved durability of open surgical repair, the initial mortality advantage of TEVAR over open surgical repair persisted for until nine years post-operatively, resulting in a significant survival benefit associated with TEVAR. They proposed TEVAR ought to be considered as first-line therapy among Medicare beneficiaries, and open surgical repair be restricted to high-volume centers and patients with a low risk of perioperative mortality. However, Desai et al. [13] reviewed their series of patients who had descending thoracic aortic aneurysms repaired by either TEVAR or open repair. They concluded that 105 patients in the TEVAR group clearly had undergone more reinterventions than 45 patients who underwent open repair. The TEVAR cohort had a trend towards a decreased 30-day mortality as well as decreased rates of neurologic complications; however, none of these findings reached statistical significance. During a long-term follow-up from 1995 to 2007, the choice between TEVAR and open approach did not influence survival $(p=0.5)$.

In our study, TEVAR was more prevalent in terms of postoperative short-term outcomes. However, we could not conclude that TEVAR was superior to open repair in terms of SCI, 30-day mortality, and in-hospital mortality. Furthermore, there was no significant difference in the long-term follow-up survival between the two approaches. We hypothesized that these advantages of TEVAR, i.e., less invasiveness and ease of use, will provide improved long-term results for the patients.
Similar to the previous study, our findings indicated that TEVAR was better than open repair in terms of short-term outcomes; however, the long-term results were similar in both groups. Considering the fact that the previous studies had data older than in this study and there were discrepancies in the age or number of patients between the two groups, we believe that this study, which used PSM to neutralize the effects of confounding independent variables, presents more accurate data on the long-term results of the two groups.

In case of reintervention rates, there were significantly reinterventions in the TEVAR group than in the open repair group. Moreover, although long-term survival of the two groups did not differ significantly, more reinterventions occurred in the TEVAR group; the costs of additional graft modules to treat endoleaks and follow-up CT scans increase hospital cost, attributing to the disadvantage of TEVAR. Furthermore, while TEVAR had lesser procedure-related complications than open repair; patients had more adverse events, such as re-dissection, fistula formation and stent-graft infection. This should be considered in the choice of approach.

Some authors have proposed that TEVAR does not change the natural history of the disease, and although less invasive, may be inferior to open therapies [27]. In our present study, the maximal aortic size decreased more in the open repair group than in the TEVAR group, but not dramatically. This supports the report that it does not alter natural history of aortic pathologies, and, emphasizes the importance of long -term follow up. For this reason, in patients requiring TEVAR, the establishment of a precise TEVAR indication 
will reduce the requirement for further reintervention; better results are expected with improvements in debranching skills and stent- graft development.

Our study has several limitations. First, it was a single-center retrospective study that included a small number of patients, with a possible selection bias that might have affected our results. Second, the difference of follow-up duration and frequency can affect the survival rate of both groups. We performed PSM attempts to reduce the bias due to confounding variables. However, since TEVAR was introduced in 2007, it has a relatively short follow-up duration, whereas more frequent follow-up to monitor stent- grafts is expected to affect the results. Finally, the functional status of patient information influenced treatment strategy; there was no data interpretation, and studies on cost analysis, which is an increasingly important consideration for treatment strategy, have not been conducted. The results, which include all of these, may influence the final assessment of quality of life and longer life expectancy.

\section{Conclusions}

In conclusion, our study showed that a long-term comparison between open repair and TEVAR demonstrated similar results in patients with descending aortic pathologies. However, patients who underwent TEVAR showed superior short-term recovery outcomes and a higher reintervention rate than the open repair group. Larger multicenter population studies that consider quality of life could support our results.

\section{Abbreviations \\ TEVAR: Thoracic endovascular aortic repair; PSM: Propensity score match- ing; PAU: Penetrating atherosclerotic ulcer; CT: Computed tomography; SD: Standard deviation; IQR: Interquartile range; HRs: Hazard ratios; Cls: Confidence intervals; AKI: Acute kidney injury; CRF: Chronic renal failure; SCI: Spinal cord} ischemia.

\section{Acknowledgements}

We certify that this research is our own work and all sources of information used in this research have been fully acknowledged.

\section{Authors' contributions}

SS collected the case data and drafted the original manuscript. JC and HJ operated and treated the patients and critically reviewed the manuscript. All authors read and approved the final manuscript.

\section{Funding}

None of the authors have any financial interests to disclose.

\section{Availability of data and materials}

The datasets used and/or analyzed during the current study are available from the corresponding author on reasonable request.

The datasets used and/or analyzed during the current study are available from the Department of Thoracic and Cardiovascular Surgery, Kyungpook National University, Kyungpook National University Hospital, on reasonable request.

\section{Ethics approval and consent to participate}

The institutional review board (IRB) of Kyungpook National University Hospital approved this retrospective study and waived the requirement for individual patient consent (IRB approval No. 2019-10-051).

\section{Consent for publication}

Not applicable.

\section{Competing interests}

The authors declare that they have no conflict of interest.

\section{Author details}

${ }^{1}$ Trauma Center, Department of Thoracic and Cardiovascular Surgery, School of Medicine, Kyungpook National University, Kyungpook National University Hospital, Daegu, Republic of Korea. ${ }^{2}$ Department of Thoracic and Cardiovascular Surgery, School of Medicine, Kyungpook National University, Kyungpook National University Hospital, 130 Dongdeok-ro, Jung-gu, Daegu, Republic of Korea.

Received: 21 July 2020 Accepted: 22 October 2020

Published online: 03 November 2020

\section{References}

1. Fairman RM, Criado F, Farber M, Kwolek C, Mehta M, White R, Lee A, Tuchek JM, Investigators V. Pivotal results of the Medtronic Vascular Talent Thoracic Stent Graft System: the VALOR trial. J Vasc Surg. 2008;48(3):546-54.

2. Matsumura JS, Cambria RP, Dake MD, Moore RD, Svensson LG, Snyder S, Investigators TXCT. International controlled clinical trial of thoracic endovascular aneurysm repair with the Zenith TX2 endovascular graft: 1-year results. J Vasc Surg. 2008;47(2):247-57 ((discussion 257))

3. Makaroun MS, Dillavou ED, Kee ST, Sicard G, Chaikof E, Bavaria J, Williams D, Cambria RP, Mitchell RS. Endovascular treatment of thoracic aortic aneurysms: results of the phase II multicenter trial of the GORE TAG thoracic endoprosthesis. JVasc Surg. 2005;41(1):1-9.

4. Gopaldas RR, Huh J, Dao TK, LeMaire SA, Chu D, Bakaeen FG, Coselli JS. Superior nationwide outcomes of endovascular versus open repair for isolated descending thoracic aortic aneurysm in 11,669 patients. J Thorac Cardiovasc Surg. 2010;140(5):1001-10.

5. Zhang L, Zhao Z, Chen Y, Sun Y, Bao J, Jing Z, Zhou J. Reintervention after endovascular repair for aortic dissection: A systematic review and metaanalysis. J Thorac Cardiovasc Surg. 2016;152(5):1279-88.

6. Hua HT, Cambria RP, Chuang SK, Stoner MC, Kwolek CJ, Rowell KS, Khuri SF, Henderson WG, Brewster DC, Abbott WM. Early outcomes of endovascular versus open abdominal aortic aneurysm repair in the National Surgical Quality Improvement Program-Private Sector (NSQIP-PS). J VasC Surg. 2005;41(3):382-9.

7. Hansen CJ, Bui H, Donayre CE, Aziz I, Kim B, Kopchok G, Walot I, Lee J, Lippmann M, White RA. Complications of endovascular repair of high-risk and emergent descending thoracic aortic aneurysms and dissections. J Vasc Surg. 2004;40(2):228-34.

8. Fillinger MF, Greenberg RK, McKinsey JF, Chaikof EL. Society for Vascular Surgery Ad Hoc Committee on TRS: reporting standards for thoracic endovascular aortic repair (TEVAR). J Vasc Surg. 2010;52(4):1022-33.

9. Lee HC, Joo HC, Lee SH, Lee S, Chang BC, Yoo KJ, Youn YN. Endovascular repair versus open repair for isolated descending thoracic aortic aneurysm. Yonsei Med J. 2015;56(4):904-12.

10. Desai ND, Burtch K, Moser W, Moeller P, Szeto WY, Pochettino A, Woo EY, Fairman RM, Bavaria JE. Long-term comparison of thoracic endovascular aortic repair (TEVAR) to open surgery for the treatment of thoracic aortic aneurysms. J Thorac Cardiovasc Surg. 2012;144(3):604-9 ((discussion 609-611)).

11. Mitchell RS, Ishimaru S, Ehrlich MP, Iwase T, Lauterjung L, Shimono T, Fattori R, Yutani C. First International Summit on Thoracic Aortic Endografting: roundtable on thoracic aortic dissection as an indication for endografting. J Endovasc Ther. 2002;9(Suppl 2):I198-105. 
12. Harky A, Kai Chan JS, Ming Wong CH, Bashir M. Open versus endovascular repair of descending thoracic aortic aneurysm disease: a systematic review and meta-analysis. Ann Vasc Surg. 2019;54(304-315):e305.

13. Adams JD, Angle JF, Matsumoto AH, Peeler BB, Arslan B, Cherry KJ, Kern $J A$, Dake MD. Endovascular repair of the thoracic aorta in the post-FDA approval era. J Thorac Cardiovasc Surg. 2009;137(1):117-23.

14. Dake MD, Miller DC, Semba CP, Mitchell RS, Walker PJ, Liddell RP. Transluminal placement of endovascular stent-grafts for the treatment of descending thoracic aortic aneurysms. N Engl J Med. 1994;331(26):1729-34.

15. Cambria RP, Clouse WD, Davison JK, Dunn PF, Corey M, Dorer D. Thoracoabdominal aneurysm repair: results with 337 operations performed ove a 15-year interval. Ann Surg. 2002;236(4):471-9 ((discussion 479)).

16. Huynh TT, Miller CC 3rd, Estrera AL, Porat EE, Safi HJ. Thoracoabdominal and descending thoracic aortic aneurysm surgery in patients aged 79 years or older. J Vasc Surg. 2002;36(3):469-75.

17. Zhang H, Wang ZW, Zhou Z, Hu XP, Wu HB, Guo Y. Endovascular stentgraft placement or open surgery for the treatment of acute type B aortic dissection: a meta-analysis. Ann Vasc Surg. 2012;26(4):454-61.

18. Orandi BJ, Dimick JB, Deeb GM, Patel HJ, Upchurch GR Jr. A populationbased analysis of endovascular versus open thoracic aortic aneurysm repair. J Vasc Surg. 2009;49(5):1112-6.

19. Stone DH, Brewster DC, Kwolek CJ, Lamuraglia GM, Conrad MF, Chung TK, Cambria RP. Stent-graft versus open-surgical repair of the thoracic aorta: mid-term results. J Vasc Surg. 2006:44(6):1188-97.

20. Coselli JS, Bozinovski J, Cheung C. Hypothermic circulatory arrest: safety and efficacy in the operative treatment of descending and thoracoabdominal aortic aneurysms. Ann Thorac Surg. 2008;85(3):956-63 ((discussion 964)).

21. Huynh TT, van Eps RG, Miller CC 3rd, Villa MA, Estrera AL, Azizzadeh A, Porat EE, Goodrick JS, Safi HJ. Glomerular filtration rate is superior to serum creatinine for prediction of mortality after thoracoabdominal aortic surgery. J Vasc Surg. 2005;42(2):206-12.

22. Wong DR, Parenti JL, Green SY, Chowdhary V, Liao JM, Zarda S, Huh J, LeMaire SA, Coselli JS. Open repair of thoracoabdominal aortic aneurysm in the modern surgical era: contemporary outcomes in 509 patients. J Am Coll Surg. 2011;212(4):569-79 ((discussion 579-581)).

23. Estrera AL, Miller CC 3rd, Chen EP, Meada R, Torres RH, Porat EE, Huynh TT, Azizzadeh A, Safi HJ. Descending thoracic aortic aneurysm repair: 12-year experience using distal aortic perfusion and cerebrospinal fluid drainage. Ann Thorac Surg. 2005;80(4):1290-6 ((discussion 1296)).

24. Bavaria JE, Appoo JJ, Makaroun MS, Verter J, Yu ZF, Mitchell RS, Gore TAGI. Endovascular stent grafting versus open surgical repair of descending thoracic aortic aneurysms in low-risk patients: a multicenter comparative trial. J Thorac Cardiovasc Surg. 2007;133(2):369-77.

25. Conrad MF, Ergul EA, Patel VI, Paruchuri V, Kwolek CJ, Cambria RP. Management of diseases of the descending thoracic aorta in the endovascular era: a Medicare population study. Ann Surg. 2010;252(4):603-10.

26. Goodney PP, Travis L, Lucas FL, Fillinger MF, Goodman DC, Cronenwett $J$, Stone DH. Survival after open versus endovascular thoracic aortic aneurysm repair in an observational study of the Medicare population. Circulation. 2011;124(24):2661-9.

27. Elefteriades JA, Farkas EA. Thoracic aortic aneurysm clinically pertinent controversies and uncertainties. J Am Coll Cardiol. 2010;55(9):841-57.

\section{Publisher's Note}

Springer Nature remains neutral with regard to jurisdictional claims in published maps and institutional affiliations.
Ready to submit your research? Choose BMC and benefit from:

- fast, convenient online submission

- thorough peer review by experienced researchers in your field

- rapid publication on acceptance

- support for research data, including large and complex data types

- gold Open Access which fosters wider collaboration and increased citations

- maximum visibility for your research: over 100M website views per year

At BMC, research is always in progress.

Learn more biomedcentral.com/submissions 